\title{
THE ARGONNE WAKEFIELD ACCELERATOR: UPGRADE SCENARIOS AND FUTURE EXPERIMENTS CONF-97050 Z--
}

\author{
W. Gai, M. Conde, R. Konecny, X. Li, J. Power, P. Schoessow and J. SimpsonRECEIVA \\ Argonne National Laboratory, Argonne, IL 60439, USA
}

\begin{abstract}
The Argonne Wakefield Accelerator is presently operational and nearing completion of its initial dielectric structure- and plasma-based experimental program. In this paper a number of possible future improvements and directions for the AWA are discussed including photocathode source upgrades, laser pulse and beam shaping options, multiple drive bunch generation, and novel wakefield device measurements. Plans for a 1 $\mathrm{GeV}$ demonstration wakefield accelerator will be presented.
\end{abstract}

\section{INTRODUCTION}

Generating and accelerating high charge and short electron beams have been one of the areas of study for the Argonne Wakefield Accelerator. So far, AWA has demonstrated the capability of producing $100 \mathrm{nC}, 20-$ 30 ps (FWHM) electron beams at $14 \mathrm{MeV}$. This unprecedented performance was obtained using a novel half cell photocathode gun cavity and two standing wave iris-loaded linac sections $[1,2]$. The AWA machine has reached its design goal and has been used for dielectric wakefield [3] and plasma [4] experiments. The initial results are encouraging. Achieving higher gradients in wakefield experiments would require the drive electron pulse to be even shorter and have a lower emittance. Another requirement for both high gradient and sustained wakefield acceleration is that a pulse train of electron bunches with the same high charge and short length must be used [5]. In this paper, we describe near term and future experimental plans using the existing facility and present proposed upgrade plans for the AWA, including: a) A new gun design which when used with one of the "existing AWA linac cavities will produce $100 \mathrm{nC}, 1.2 \mathrm{~mm}(4 \mathrm{ps}) \mathrm{rms}, 400 \mathrm{~mm} \mathrm{mrad}$ normalized emittance and $17 \mathrm{MeV}$ electron beams; b) Multiple pulse operation with trains of $20-4040 \mathrm{nC}$ pulses using laser photocathode based technology or a novel high current micropulse gun (HQMG); c) Upgrade of the AWA drive linac to $100 \mathrm{MeV}$ with the capability of accelerating $20-100$ electron pulses at $40 \mathrm{nC}$ /pulse. We discuss the impact of these upgrades and propose a scheme to demonstrate $1 \mathrm{GeV}$ beam acceleration using dielectric wakefield acceleration technology.

\section{NEAR TERM AWA PROJECTO \$ TI}

Although the primary thrust of this report involves possible upgrades to the facility itself, it is important to mention planned areas of research in the near term which will use the existing AWA facility.

- Study the beam generation, formation and emittance growth in the high current linac.

- Study methods to longitudinally shape the drive beam, in particular to generate a triangular profile. This will be used to demonstrate transformer ratio enhancement in both plasma and structure wakefield experiments [6].

- Continuation of the plasma wakefield experiment in both linear and non-linear regimes.

- Dielectric wakefield transformer.

The dielectric wakefield transformer [7] is of particular interest as offering the best candidate technology for practical high energy acceleration. Briefly, the wakefield generated by a drive bunch in a low impedance dielectric structure is coupled to a high impedance dielectric structure. The of pulse experiences both transverse and longitudinal compression in the high impedance device. High net acceleration can be realized if a train of 10-20 drive bunches is used.

Initial experiments will use a single drive bunch with the goal of observing the gradient step-up and studying optimal coupling between the two structures. Based on the performance of the AWA drive linac, we expect to produce a gradient of $80-100 \mathrm{MeV} / \mathrm{m}$ at a transformer ratio of 5 . Some relevant work on designing efficient if coupling to dielectric structures is found in [14].

\section{PHOTOCATHODE GUN UPGRADES}

Rf photocathode technology has experienced tremendous growth since its first invention[8]. To date, most if PC sources were developed to produce low charge but high brightness beams as injectors for FELs and other applications[9]. In order to achieve high gradient wakefield acceleration, we have designed, fabricated and commissioned a high current $(100 \mathrm{nC}, 20-30 \mathrm{ps})$ half cell L-band gun with two additional linac sections [1]. However, the present gun was designed with the constraint that only $1.5 \mathrm{MW}$ rf power would be initially available at the AWA. Thus the gun was designed with high shunt impedance and with output energy of 1.5 $\mathrm{MeV}$.

Submitted to the proceedings of the 1997 Particle Accelerator Conference. Vancouver BC, May 12-16, 1997. 


\section{DISCLAIMER}

This report was prepared as an account of work sponsored by an agency of the United States Government. Neither the United States Government nor any agency thereof, nor any of their employees, makes any warranty, express or implied, or assumes any legal liability or responsibility for the accuracy, completeness, or usefulness of any information, apparatus, product, or process disclosed, or represents that its use would not infringe privately owned rights. Reference herein to any specific commercial product, process, or service by trade name, trademark, manufacturer, or otherwise does not necessarily constitute or imply its endorsement, recommendation, or favoring by the United States Government or any agency thereof. The views and opinions of authors expressed herein do not necessarily state or reflect those of the United States Government or any agency thereof. 


\section{DISCLAMIXR}

Portions of this docmenent may be illegible in electronic image prodinets. Inoges are produced fram the best available original docementert 
The present gun was designed to operate with a peak photocathode field of $92 \mathrm{MV} / \mathrm{m}$. During initial tests the interior of the gun was damaged by a vacuum window failure while under full of power. Although the gun is reaching its design goals, depression of the photocathode field by dark current emission limits further performance improvement. Reaching and exceeding $10 \mathrm{kA}$ will require a new gun cavity.

One option is to build a copy of the high current gun cavity with improved surface preparation and conditioning procedures. We are presently collaborating with SSRC (Taiwan) to duplicate our current gun design. We plan to use the dielectric coating technology developed by FM Technologies, which would enhance the rf surface field on the cathode and minimize the dark current (by a factor of 100), thus reducing the electron pulse length.

Another possibility is to implement an improved gun design. In this section, we show that a new design philosophy making use of $10 \mathrm{MW}$ or more if power available for the drive gun can produce the desired performance improvement for the AWA drive beam.

\section{$1-1 / 2$ Cell Design}

The choice for this new gun design is Brookhaven type [10] $1-1 / 2$ cell as shown in Figure 1. Although the beam will have lower emittance if one chooses a multi-cell gun cavity, the if power requirements will be excessive. There have been designs of relatively high charge L-band guns at APEX[11] and TTF[12], but they produce relatively long beams with moderate charges $(<10 \mathrm{nC})$. Magnetic compression is then used after the gun to produce short

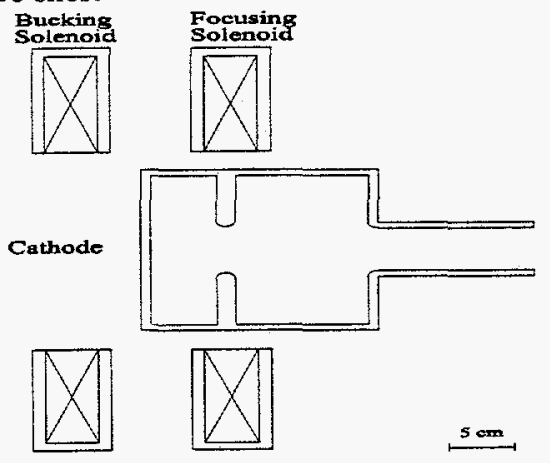

Figure 1. Schematic of proposed $1-1 / 2$ cell drive gun for the AWA upgrade.

bunches. In our case we require much higher charges with the pulse length remaining short $(<10 \mathrm{ps})$. The key to designing a high charge short pulse electron gun is the use of a high photocathode electric field. The computer codes SUPERFISH and PARMELA were used to model cavity fields and beam dynamics respectively.
In Figure 2, we show the effect of the peak surface electric field on the rms bunch length and emittance. At $100 \mathrm{MV} / \mathrm{m}$ surface field along with other optimized parameters, one can achieve $\sigma_{\mathrm{z}}=1.2 \mathrm{~mm}(4 \mathrm{ps})$ and $\varepsilon_{\mathrm{N}}=$ $400 \mathrm{~mm}$ mrad.

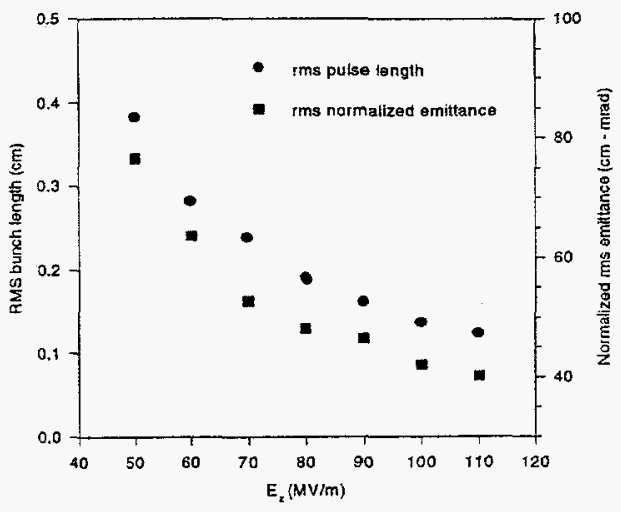

Figure 2. Pulse length and emittance vs $E_{z}$ (with optimized solenoid design)

Rms Bunch Length in the 1 \& Half Celis Gun

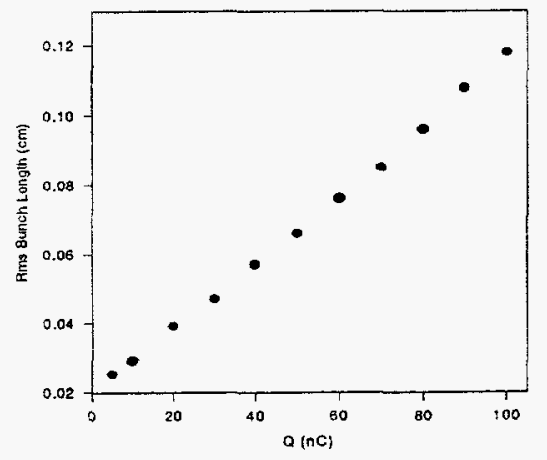

Figure 3. $\sigma_{7}$ vs charge in the $1-1 / 2$ cell gun.

Normalized Emittance in the 1 \& half cetis gun

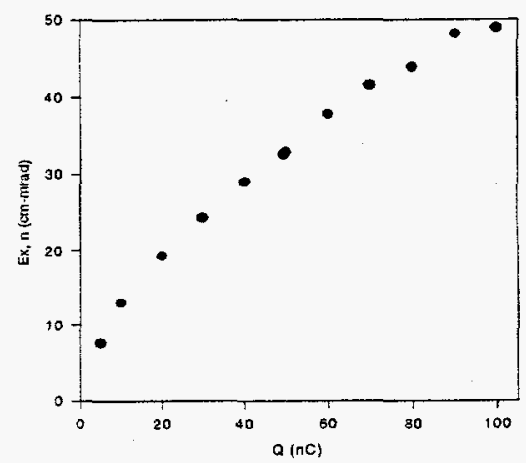

Figure 4. Transverse emittance vs charge

For the $100 \mathrm{nC}$ beam case, the rms pulse length is 1.2 $\mathrm{mm}$ and normalized emittance is in the range of $300-400 \mathrm{~mm} \mathrm{mrad}$. This is a great improvement over 
the existing AWA gun design ( $\sigma_{\mathrm{z}}=3 \mathrm{~mm}$, and $\varepsilon_{\mathrm{N}}=800$ mm mrad).

The use of a single AWA linac tank operated at 10 MW in conjunction with the new gun will produce a drive beam energy of $15-20 \mathrm{MeV}$ with electron bunch parameters as above. Numerical simulations indicate that with these parameters the drive beam could generate wakefield gradients in excess of $1 \mathrm{GeV} / \mathrm{m}$ in plasma with density of $7 \times 10^{13} \mathrm{~cm}^{-3}$. For dielectric structures, the reduced emittance and bunch length will permit $100 \mathrm{MV} / \mathrm{m}$ gradients to be attained for collinear drive-witness geometries. This second generation AWA high current gun builds upon our experience with the original high current gun and pushes the technology frontier further into this previously unexplored region of photocathode source parameter space.

\section{MULTI-PULSE UPGRADE OPERATION}

As discussed in section II, operation of the dielectric wakefield transformer at high gradients over extended distances requires the use of a long pulse train drive beam ( $20-40$ pulses of $40 \mathrm{nC}$ each). One way to achieve this mode of operation at the AWA is to use a laser pulse train to generate the electron pulse train. We have obtained a laser pulse splitter which will provide 16 pulses with 760 ps spacing (i.e. one if period at 1.3 $\mathrm{GHz}$ ). Thus if sufficient laser power is available, this will enable us to study the technical challenges associated with production and acceleration of multipulse high current beams using if photocathode methods.

Another way to generate bunch trains is to replace the photoinjector with the high current micropulse gun currently under development by FM Technologies[13]. This gun will produce up to $40 \mathrm{nC}$ bunches with rms pulse length of $10 \mathrm{ps}$. The advantage of this gun is that the beam produced is very stable and repeatable compared to laser photocathode techniques. It eliminates completely the need for the laser and the complications of beam splitting optics. The of gun designed in the section III can be modified to be used as an injector post acceleration cavity for the micropulse gun. A preliminary study shows that this technology can produce up to $4 \mathrm{MeV}$ beam with the emittance and pulse length preserved as in the case of the new photoinjector design described above.

\section{LINAC UPGRADE TO 100 MEV DRIVE BEAM/ 1 GEV WAKEFIELD ACCELERATOR}

In order to demonstrate wakefield acceleration concepts at high energy, one needs to increase the drive beam energy. As indicated by our previous study, higher drive beam energy leads to higher wakefield gradients over longer acceleration distances [5]. The AWA Linac design has demonstrated high current electron beams ( 100 $\mathrm{nC})$ with relative low momentum spread $(<10 \%)$ and emittance $(600 \mathrm{~mm}$ mrad $\mathrm{rms}$ normalized). Thus we anticipate the same linac cavity design will be used to accelerate the drive beam to the desired energy, simply by the addition of five new linac cavities and three new if stations.

For a $1 \mathrm{GeV}$ wakefield accelerator demonstration, one needs to operate the $100 \mathrm{MeV}$ drive linac in multipulse mode (20 pulses/rf macropulse each with $40 \mathrm{nC}$ charge). The dielectric wakefield transformer described above would then provide the additional $1 \mathrm{GeV}$ of acceleration [3].

\section{SUMMARY}

The AWA facility has attained its challenging design goals and is presently in the midst of its experimental program. A number of performance improvements requiring significant machine upgrades are under consideration. We have described several AWA upgrade scenarios and plans: if photocathode gun upgrades, multiple pulse operation and linac energy upgrades. We have shown a practical scheme using a dielectric step-up transformer and upgraded AWA machine to accelerate a beam to $1 \mathrm{GeV}$ using wakefield technology.

\section{ACKNOWLEDGEMENT}

This work is supported by DOE, High Energy Physics Division, Advanced Technology Branch under the contract No. W-31-109-ENG-38.

\section{REFERENCES}

1. P. Schoessow et. al., Proceedings of Particle Accelerator Conference, p976-978., 1995

2. M. Conde et. al., in this Proceedings

3. P. Schoessow et al., in this Proceedings

4. N. Barovet. al., in this Proceedings and submitted to Phys. Rev. Lett. (1997)

5. W. Gai et al, Phys. Rev. E, 55, 3, p3481, (1997)

6. K. Bane et al., IEEE Trans. Nucl. Sci., NS-32, 3524 (1985)

7. E. Chojnacki et al., Proceedings of 1993 Particle Accelerator Conference, pp. 2557-2559.

8. J. Fraser et al., IEEE Trans. Nucl. Sci., NS-32,p.1719 (1985)

9. C. Travier, in AIP Proceedings, No. 335, p57 (1994)

10. K. Batchelor et al, Proc. of EPAC 541 (1990)

11. B. Carlsten $e$ t al., Proceedings of Particle Accelerator Conference, p.985., 1995

12. E. Colby et al., Proceedings of Particle Accelerator Conference, p967.,1995

13. F. Mako et. al., these Proceedings

14. W.Gai, R.Konecny, J.Simpson, these Proceedings 